\title{
Electrochemical Characterization of a New Biodegradable FeMnSi Alloy Coated with Hydroxyapatite-Zirconia by PLD Technique
}

\author{
Nicanor Cimpoeşu, ${ }^{1}$ Lucia Carmen Trincă, ${ }^{2}$ Georgiana Dascălu, ${ }^{3}$ Sergiu Stanciu, ${ }^{1}$ \\ Silviu Octavian Gurlui, ${ }^{3}$ and Daniel Mareci $^{4}$ \\ ${ }^{1}$ Faculty of Materials Science and Engineering, "Gheorghe Asachi” Technical University of Iaşi, \\ Prof. Dr. Docent Dimitrie Mangeron Street No. 41, 700050 Iaşi, Romania \\ ${ }^{2}$ Faculty of Horticulture, "Ion Ionescu de la Brad" University of Agricultural Sciences and Veterinary Medicine, \\ 3 M. Sadoveanu Alley, 700490 Iaşi, Romania \\ ${ }^{3}$ Faculty of Physics, "Alexandru Ioan Cuza" University, Bulevardul Carol I, No. 11, 700506 Iași, Romania \\ ${ }^{4}$ Faculty of Chemical Engineering and Environmental Protection, "Gheorghe Asachi" Technical University of Iaşi, \\ 73 Prof. Dr. Docent Dimitrie Mangeron Street, 700050 Iaşi, Romania
}

Correspondence should be addressed to Lucia Carmen Trincă; lctrinca@uaiasi.ro

Received 11 November 2015; Revised 14 January 2016; Accepted 31 January 2016

Academic Editor: Pietro Cavallotti

Copyright (c) 2016 Nicanor Cimpoeşu et al. This is an open access article distributed under the Creative Commons Attribution License, which permits unrestricted use, distribution, and reproduction in any medium, provided the original work is properly cited.

Biodegradable alloys are very attractive biomaterials. Electrochemical impedance spectroscopy (EIS) and linear potentiodynamic polarization (LPP) techniques were used for the study of the electrochemical behavior of uncoated FeMnSi and coated FeMnSi with hydroxyapatite + zirconia $\left(\mathrm{HA}-\mathrm{ZrO}_{2}\right.$ ) through pulsed laser deposition (PLD) technique. Experiments were carried out using Hank's balanced salt solution (HBSS). It has been shown that in HBSS the impedance for uncoated FeMnSi was mainly characterized by one capacitive effect, which related to the alloy charge transfer control. The charge transfer resistance increases for $\mathrm{HA}-\mathrm{ZrO} \mathrm{r}_{2}$-coated FeMnSi alloy. The equivalent circuits simulating the electrochemical behavior of both uncoated and $\mathrm{HA}-\mathrm{ZrO}{ }_{2}-\mathrm{coated}_{\mathrm{FeMnSi}}$ alloys in HBSS were proposed. From LPP the corrosion resistance was evaluated by means of the zero current potential (ZCP) and corrosion current density $\left(j_{\text {corr }}\right)$. The surface morphology of both uncoated and HA-coated FeMnSi alloys in HBSS obtained after LPP was studied using scanning electron microscopy (SEM).

\section{Introduction}

Metallic materials are used as implant components in human body due to their biocompatibility (related to their corrosion behavior), and mechanical properties. However, the conventional metallic implants suffer a grand challenge: stress shielding which reduce the life quality. The stress shielding effect can cause bone resorption, cell death, and implant loos $[1,2]$.

Intensive efforts have been made in recent years to develop the "biodegradable implants," some nontoxic implant materials that are resorbed by the human body after a certain period of time. $\mathrm{MgCa}$ and its alloys are becoming candidates for biodegradable metallic implants due to their biocompatibility and their excellent mechanical properties [3-7]. However, the degradation rate of $\mathrm{MgCa}$ alloys can hardly meet the requirements for biomedical applications. The high corrosion rate makes the biodegradable process be faster than the time required to heal the bone [8]. Similar attempts have targeted the supplementary alloying with $\mathrm{Cr}$, $\mathrm{Cu}, \mathrm{Fe}, \mathrm{Mn}, \mathrm{Mo}$, Se, or $\mathrm{Zn}$ [9]. However, coordination is needed within the toxicology community due to the many limits variation of the different metal maximum permissible concentrations in the body [10].

The development of the biodegradable metallic materials has grown in the latest years due to the many advantages as compared with permanent implantable materials and because of the multitude of the existing medical applications [11]. 
A biodegradable implant requires only one surgery (for the implant insertion) as compared to a permanent implant for which two surgical interventions are needed (for the insertion and the removal of the implant). Besides, the risks arising from long-term implants will disappear, like chronic inflammation of the biological tissue, or side effects of their rejection in time from the biological environment.

More than $70 \%$ of the implants are made nowadays of metallic biomaterials used as structural units in reconstructive surgery. In the case of iron-based alloys, stainless steels were used as implantable materials [12]. Lately, the possibility of obtaining iron-based biodegradable materials appeared as a consequence of the outstanding results of the in vivo and in vitro tests. When implantable elements made of pure Fe [13] were used, there were no indications of local or general toxicity and also no reports of local inflammations or other clinical conditions. However, due to the low speed of degradation of pure Fe in the biological environments, these implants develop with time similar reactions with long-term implants [14]. This is the reason why Fe alloy-new products were developed aiming to reduce the corrosion resistance and accelerate the speed degradation. Compared with the magnesium alloys, Fe-Mn present degradation rates of 10 times less or more $[15,16]$ and they are considered to be inadequate for most applications of temporary implantation [17].

Hydroxyapatite $\left(\mathrm{Ca}_{10}\left(\mathrm{PO}_{4}\right)_{6}(\mathrm{OH})_{2}\right.$, HA) presents bioactive properties due to the similar mineral constitution with bones, being able to achieve a firm and direct biological fixation with the surrounding bone tissue. However, the increased degradability of HA coatings is impediment for the long-term clinical application. Zirconia $\left(\mathrm{ZrO}_{2}\right)$ has been commonly used as reinforcement for ceramics because of its chemical inertness, excellent mechanical properties, and low cytotoxicity. However, the zirconia based devices for total knee replacement showed reduced wear with respect to Co$\mathrm{Cr}$ devices, in abrasive conditions [18]. The concept of adding $\mathrm{ZrO}_{2}$ as second phase to HA determined a significant increase of the bonding strength that was reported for the implant material [19].

An ideal behavior of the biodegradable metallic materials involves the dual manifestation of these materials in the biological environment in which they operate. This duality refers to both periods in which the material must behave differently. In the first period, the metallic material must provide a very good stability of the mechanical properties to replace the first stage of recovery of the hard tissue. In the second period, the metallic element should be degraded by generalized corrosion in order to achieve the complete transition in the biological system.

The corrosion resistance of biodegradable metallic materials for biomedical applications in corrosive environments such as simulated body fluids must be improved especially in the first period of implantation. The integrity of the metallic implant in first period is important for the bone healing. A biodegradable implant can be improved by adding on the surface thin layers resistant to corrosion in order to protect the material integrity [20]. After the breakdown of the thin layer, the implant material will degrade normally.
One of the methods to improve the corrosion resistance of biodegradable alloy for biomedical applications is pulsed laser deposition (PLD). PLD has been proven to be a versatile technique which also allows the deposition of polymer thin films as first described by Hansen and Robitaille [21, 22]. The material is vaporized from the target (in a plasma plume) which will deposit it as a thin film on a substrate.

In the present study, the degradation characteristics of a new uncoated FeMnSi and $\mathrm{HA}-\mathrm{ZrO}_{2}$-coated FeMnSi alloys using PLD technique will be evaluated using electrochemical methods.

\section{Materials and Methods}

Results from literature [14] revealed the potential of Fe-base alloys as biodegradable implants. In the same time there is a necessity to increase their corrosion rate to meet the medical requirements for applications. In order to obtain an increased degradation rate of iron, the susceptibility of corrosion can be improved by addition of less noble alloying elements in the iron limit of solubility. The scope of this action is to make the iron matrix responsive to corrosion in a higher level. This approach, based on metallurgical and toxicological considerations, considers $\mathrm{Mn}$ as a suitable alloying element because Mn decreases the standard electrode potential of iron [23]. In this paper we analyze an alloy based on iron with small amounts of silicon (2 $\mathrm{wt} \%)$ and manganese (1 wt \%). The concentration of all impurities (traces of S, C or $\mathrm{N}$ ) was less than $0.1 \mathrm{wt} \%$. Silicon was added to stabilize the $\alpha$ phase solid solution at the ambient temperature in order to assure a uniform degradation. Silicon, by dissolving in the ferrite, will increase the mechanical properties of the material [24]. Also, when silicon is alloyed to pure iron, it will increase the electrical resistivity of the material by decreasing the losses through Foucault currents and will lead to a material corrosion enhancement by favoring the generalized corrosion. Adding manganese to the silicon-iron alloy will increase the elasticity limit and will improve the processing capacity of the metallic material.

2.1. Materials and Deposition Method. Commercial pure iron (99.9\%), silicon (99.999\%), and manganese (99.7\%) were melted (5 times for homogenization) in a vacuum-induction furnace (model UltraCast), under argon atmosphere to fabricate FeMnSi with low $\mathrm{Mn}$ and Si mass percentages. Parts of the FeMnSi alloy ingot were cut, through spark erosion, and heat treated at $1100^{\circ} \mathrm{C}$ for 40 minutes and slowly chilled with furnace for chemical and structural homogenization. Plates were obtained through hot rolling ( $10 \%$ reducing degree) at $900^{\circ} \mathrm{C}$ and the thickness was reduced to $1 \mathrm{~mm}$ and specimens were cut by spark erosion with gauge dimensions $1 \times 10 \times$ $10 \mathrm{~mm}$.

The chemical composition has been determined by EDS analysis using a Bruker detector (XFlash QUANTAX) on $4 \mathrm{~mm}^{2}$ surface. Chemical composition was $0.95 \mathrm{wt} \%$ $\mathrm{Mn}$ and $2.05 \mathrm{wt} \% \mathrm{Si}$ with a standard deviation of $0.1 \%$ (obtained through 30 chemical composition determinations on the same area). The above-mentioned percentages of 


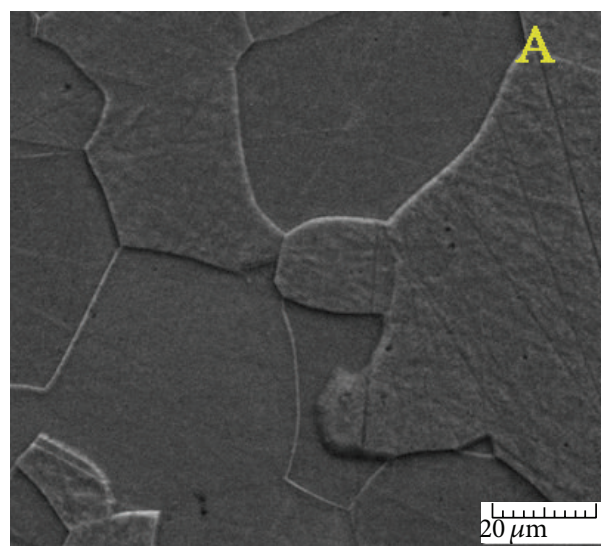

(a)

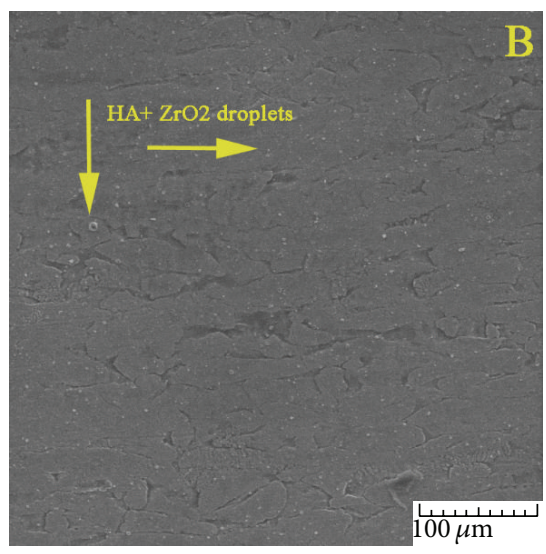

(b)

FIGURE 1: SEM micrographs of FeMnSi surface: (a) heat treated sample uncoated and (b) coated before the LPP test.

alloying elements have been calculated as average of ten values.

The depositions were done in a stainless steel vacuum chamber, equipped with a dry pump (Bluffton Motor Works) which ensured a $10^{-2}$ Torr pressure during the film growth. A thorough description of the experimental set-up is given in [25]. The $\mathrm{HA}-\mathrm{ZrO}_{2}$ target was placed on a micrometric precision $3 \mathrm{D}$ translation stage and moved constantly during deposition. The second harmonic of an Nd-YAG laser (Quantel Brilliant Easy) was focused on the bulk source material by a $35 \mathrm{~cm}$ focal point lens at a $45^{\circ}$ angle with respect to the target surface. The estimated impact area was $0.8 \mathrm{~mm}^{2}$ while the laser energy was set at $40 \mathrm{~mJ}$; this led to fluence of $\sim 5 \mathrm{~J} / \mathrm{cm}^{2}$. The FeMnSi substrate was placed at a distance of $3 \mathrm{~cm}$ from the $\mathrm{HA}$ (10 wt $\% \mathrm{ZrO}_{2}$ doped) target surface. The deposition time was $30 \mathrm{~min}$.

The surface morphology of both uncoated and $\mathrm{HA}-\mathrm{ZrO}_{2}-$ coated FeMnSi alloys before LPP test was assessed using scanning electron microscopy (VegaTescan LMH II, SE detector, $30 \mathrm{kV}$ ). The structure of FeMnSi alloy was characterized by X-ray diffraction (XRD) at ambient temperature using a Philips PW 1830/00 (Eindhoven, Netherlands) diffractometer ( $\mathrm{CuK} \alpha_{1}$ radiation). Topography of $\mathrm{HA}-\mathrm{ZrO}_{2}$-coated FeMnSi alloy was determined by atomic force microscopy (AFM) using a NanoSurf EasyScan 2 (Nanosurf AG, Liestal, Switzerland). The instrument was equipped with silicon cantilevers and easy scope video camera. The images were recorded at a scanning rate of $0.2 \mathrm{~s} \mathrm{line} \mathrm{e}^{-1}$.

\subsection{Electrochemical Tests. The solution used for electrochem-} ical test consisted of simulated physiological Hank's balanced salt solution (HBSS). The chemical composition of HBSS was presented elsewhere [26].

Both uncoated and $\mathrm{HA}-\mathrm{ZrO}_{2}$-coated FeMnSi alloy was placed in a glass corrosion flow cell kit (C145/170, Radiometer, France), which was filled with HBSS. A saturated calomel electrode was used as the reference electrode and a platinum coil as the counter electrode. The potentials in this paper are reported versus the saturated calomel electrode (SCE). The temperature of the electrochemical cell was maintained at $37 \pm 1^{\circ} \mathrm{C}$.

Electrochemical measurements were performed using a potentiostat model PARSTAT 4000 (Princeton Applied Research, NJ, USA). The instrument was controlled by a personal computer and VersaStudio software.

Electrochemical impedance spectra (EIS) were measured over a frequency range extending from $10^{5} \mathrm{~Hz}$ to $10^{-2} \mathrm{~Hz}$ using a $10 \mathrm{mV}$ amplitude AC voltage signal. The EIS tests were recorded at the open circuit potential developed by the samples after 1 hour, 1 day, and 7 days of immersion in test solution. Analysis of the spectra was performed in terms of equivalent circuit (EC) fitting using ZSimpWin software.

Linear potentiodynamic polarization (LPP) test was also carried out in HBSS, after 7 days immersion time, at $37 \pm$ $1^{\circ} \mathrm{C}$. These measurements were conducted by stepping the potential using a scanning rate of $0.5 \mathrm{mV} / \mathrm{s}$ from $-1 \mathrm{~V}$ to $+1 \mathrm{~V}$. All the polarization experiments were performed three times, to ensure the reproducibility of the results obtained.

\section{Results and Discussion}

3.1. Microstructural Characterization. Experimental results analyze the "in vitro" experiments realized by electrochemical impedance spectroscopy. Surface of FeMnSi and $\mathrm{HA}-\mathrm{ZrO}_{2}-$ coated FeMnSi alloys before the electrochemical corrosion test is presented in Figure 1. The alloy features a classical microstructure (Figure 1(a)) which consists of generally equiaxial grains with dimensions in the range: $43.26 \times$ $71.38 \mu \mathrm{m}$ (average of 50 grains) and a standard deviation of $25 \mu \mathrm{m}$.

The layer obtained by laser ablation is highly homogeneous, having nanometer size $(<100 \mathrm{~nm})[27,28]$ and with droplets characteristic for medium pressure deposits (Figure 1(b)). Droplets have dimensions between hundreds of $\mathrm{nm}$ and $2-3 \mu \mathrm{m}$, are homogeneously distributed on top of surface, and have the same composition as the target.

The $\mathrm{HA}-\mathrm{ZrO}_{2}$-coated FeMnSi alloy was found to be complex structure consisting of $\gamma$ austenite and $\varepsilon$ martensite phase by X-ray diffraction as shown in Figure 2. Indeed, all the peaks in the diffractogram were unambiguously indexed 
TABLE 1: Chemical analysis for $\left(\mathrm{HA}-\mathrm{ZrO}_{2}\right)$ coated FeMnSi alloy as determined from EDX test.

\begin{tabular}{lccccccccccc}
\hline Elements & $\mathrm{Fe}$ & $\mathrm{O}$ & $\mathrm{Si}$ & $\mathrm{Na}$ & $\mathrm{P}$ & $\mathrm{Mg}$ & $\mathrm{Zr}$ & $\mathrm{C}$ & $\mathrm{Mn}$ & $\mathrm{Ca}$ & $\mathrm{Cl}$ \\
\hline wt.\% & 61.3 & 18.9 & 6.1 & 4.2 & 2.2 & 0.6 & 0.7 & 0.5 & 1.7 & 3.6 & 0.8
\end{tabular}

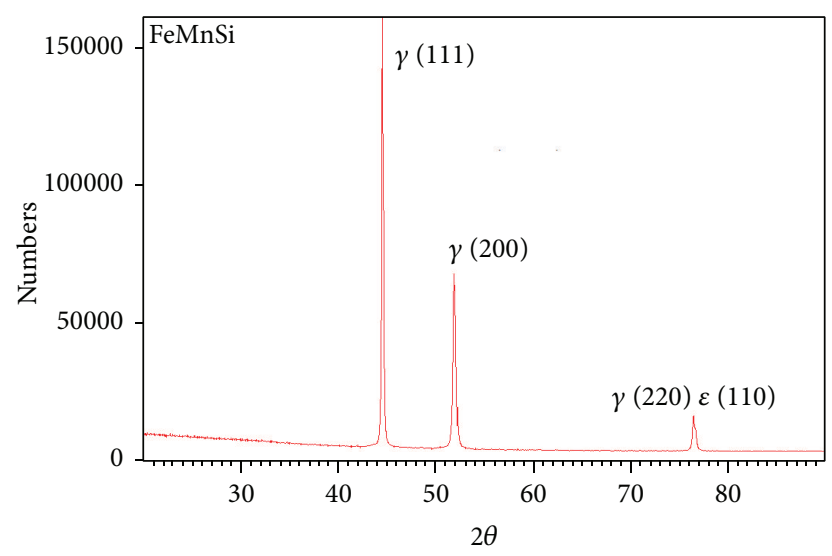

Figure 2: XRD patterns of $\mathrm{HA}-\mathrm{ZrO}_{2}$-coated FeMnSi alloy.

according to this structure, and the corresponding diffracted planes are indicated in the plot.

The EDX analysis of $\mathrm{HA}-\mathrm{ZrO}_{2}$ deposited thin film on the surface of FeMnSi sample is shown in Figure 3. The chemical analysis reveals that the $\mathrm{Ca} / \mathrm{P}$ ratio in the $\mathrm{HA}-\mathrm{ZrO}_{2}$-coated thin film is $1.65 \pm 0.03$, being very close to the theoretical value (1.67 in HA). The EDX spectrum highlights also the presence of $\mathrm{Zr}$ in the thin film deposited on FeMnSi alloy.

Chemical analysis parameters of the $\mathrm{HA}-\mathrm{ZrO}_{2}$-coated FeMnSi alloy as determined from EDX images are listed in Table 1.

Surface roughness of the samples was determined by atomic force microscopy analysis. A rugged surface was observed for $\mathrm{HA}-\mathrm{ZrO}_{2}$-coated FeMnSi alloy (Figure 4).

\subsection{Electrochemical Impedance Spectroscopy. The EIS results} are presented in the form of Nyquist plots in which the imaginary impedance $\left(Z_{\text {im }}\right)$ is plotted against the real impedance $\left(Z_{\mathrm{re}}\right)$.

Figure 5(a) shows the Nyquist plots obtained for uncoated FeMnSi alloy, at open circuit potential, after 1 hour, 1 day, and 7 days of immersion in HBSS. The Nyquist plot of uncoated FeMnSi alloy shows one capacitive arc in the high and intermediate frequency all three immersion times. The capacitive arc is associated with the dielectric properties of the corrosion products layer formed on the alloy surface. As the immersion time increases the dimension of the plot decreases indicating that the corrosion resistance of the uncoated FeMnSi alloy decreased. Bode spectra recorded at open circuit potential, with the uncoated FeMnSi alloy for different periods of time in $\mathrm{HBSS}$, at $37^{\circ} \mathrm{C}$, are shown in Figure 5(b). The Bode phase plots show one relaxation time constants; that is, one peak is observed in the Bode phase plots. The impedance values of 1-hour immersion are larger than that of 1 day and 7 days of immersion. This aspect can
TABLE 2: Electrochemical parameters obtained from EIS spectra using the selected EC for the uncoated FeMnSi alloy after different immersion time in $\mathrm{HBSS}$, at $37^{\circ} \mathrm{C}$.

\begin{tabular}{lccc}
\hline Time & $Q_{1}\left(\mu \mathrm{S} \mathrm{cm}^{-2} \mathrm{~s}^{n}\right)$ & $n_{1}$ & $R_{1}\left(\mathrm{k} \Omega \mathrm{cm}^{2}\right)$ \\
\hline 1 hour & 56 & 0.80 & 1.5 \\
1 day & 57 & 0.80 & 1.3 \\
7 days & 58 & 0.79 & 0.8 \\
\hline
\end{tabular}

be attributed to the formation of a more compact corrosion products layer after short immersion time in HBSS.

Analysis of Bode spectra in terms of an equivalent circuit (EC) allowed the values of the impedance parameters.

The EIS spectrum measured for uncoated FeMnSi alloy in HBSS, at $37^{\circ} \mathrm{C}$, could be satisfactorily fitted with the model presented in Figure 6(a). The experimental data show good fitting and an error smaller than $5 \%$. Table 2 shows the results of the fits.

Constant phase elements (CPE) were used instead of pure capacitances because of the nonideal capacitive response due to surface inhomogeneities present on the FeMnSi surface [29]. The impedance representation of CPE is given by

$$
Z_{(\mathrm{CPE})}=\frac{1}{Y_{0}(j \omega)^{n}}
$$

where $\omega$ is the angular frequency and $Y_{0}$ is a constant and the value of the exponent $n$ indicates the deviation from ideal capacitive behavior (e.g., when $n=1$ ).

$R_{\text {sol }}$ is the resistance of solution occurring between the sample and the reference electrode. This parameter has a value around $70 \pm 2 \Omega \mathrm{cm}^{2}$ in HBSS and is not listed in Table 2 . The $R_{1}$ and $Q_{1}$ parameters describe the charge transfer resistance and the constant phase elements of the corrosion products layers. The values of $R_{1}$ decrease by increasing the immersion time. These results indicate the failure of the surface corrosion products layer.

Figure 7(a) shows Nyquist diagram for the $\mathrm{HA}-\mathrm{ZrO}_{2}-$ coated FeMnSi alloy in HBSS after different immersion times. All three Nyquist diagrams indicate that the results describe two depressed, capacitive-like semicircles, one at high frequencies and another at intermediate and lower frequency values.

Also, the Bode phase spectra (Figure 7(b)) correspond to systems exhibiting two time constants as revealed by the presence of two maxima in these diagrams. That is, they can be divided into two distinct frequency ranges: the time constant in the high frequency part, which arises from uncompensated ohmic resistance resulting from the penetration of the electrolyte through a porous coating layer and the low frequency part accounting for the processes taking place at the substrate/electrolyte interface.

The impedance spectra obtained at different exposure times could be quality fitted with the equivalent circuit given in Figure 7(b). The EC is based on the consideration of a twolayer model for the surface and represents the electrochemical behavior of a metal covered with an unsealed porous layer [30-35]. The resultant EIS parameters are given in Table 3. 


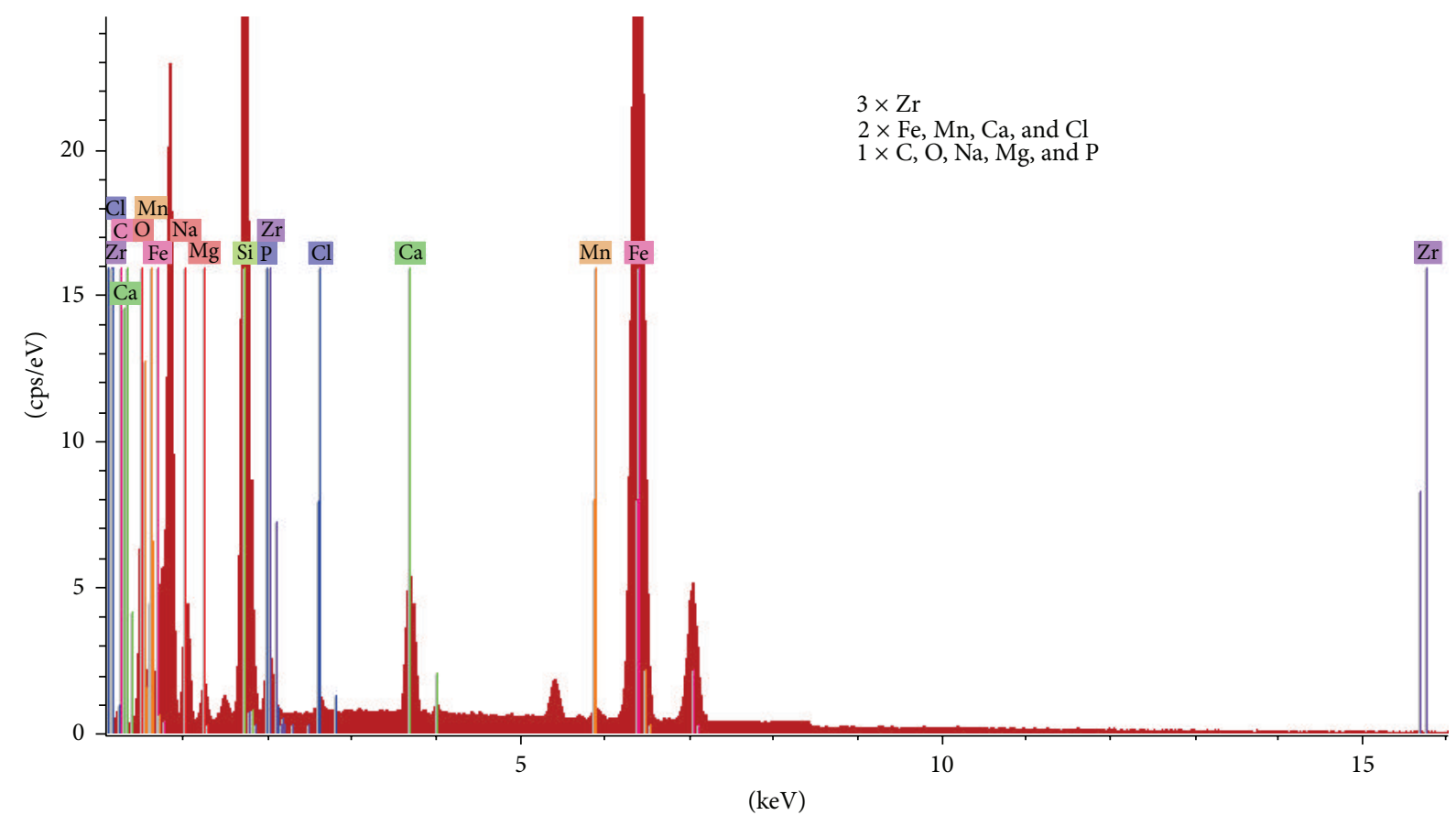

Figure 3: Representative X-ray spectrum of elements identified by EDX from FeMnSi after PLD coating with $\mathrm{HA}_{2} \mathrm{ZrO}_{2}$.

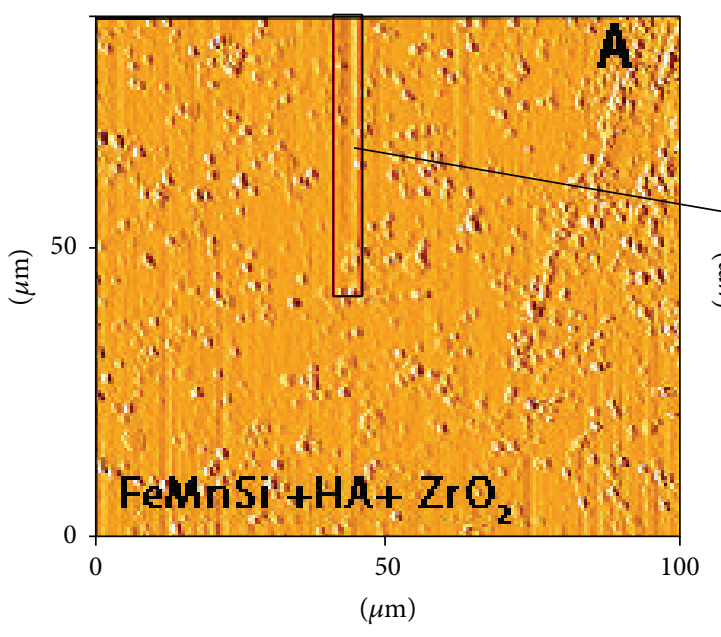

(a)

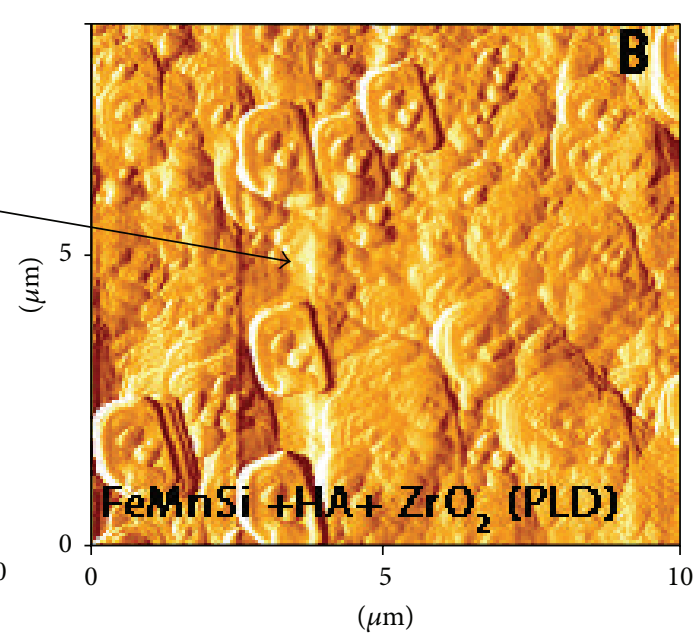

(b)

Figure 4: AFM surface topography for $\mathrm{HA}-\mathrm{ZrO}_{2}$-coated FeMnSi alloy. (a) 100 and (b) $10 \mu \mathrm{m}$ width analyze area.

The $R_{1}$ and $Q_{1}$ parameters describe the processes occurring at electrolyte/coating layer. $R_{1}$ is the pore resistance due to the penetration of the electrolyte through the pores or pinholes existing in the coated layer and $Q_{1}$ corresponds to capacitance of the coating layer. Parameter $R_{2}$ coupled with $Q_{2}$ describes the processes at the electrolyte/substrate layer interface. $R_{2}$ is the charge transfer resistance at the electrolyte/substrate interface in the pores and $Q_{2}$ is the constant phase element at the electrolyte/substrate layer interface.

From the fitted values of Table 3, some differences between the characteristics of coated layer are observed. In fact, the $R_{1}$ values determined for each time of immersion are smaller than $R_{2}$, thus indicating that the coating layer is less protective in these environments. However, both resistances $R_{1}$ and $R_{2}$ values of $\mathrm{HA}-\mathrm{ZrO}_{2}$-coated FeMnSi alloy decrease with immersion times.

Despite the protecting effect of $\mathrm{HA}-\mathrm{ZrO}_{2}$ in the coating for the protection of the FeMnSi alloy for more extended period of time, the poor sealing capacity of the coating is responsible for the later deterioration of the electrochemical behavior of the system. In fact, new ionic pathways are developed through the coatings that probably lead to the exposure of the underlying FeMnSi alloy to the HBSS. However, the charge transfer resistances for $\mathrm{HA}$-coated $\mathrm{FeMnSi}$ are higher than uncoated FeMnSi alloy. 


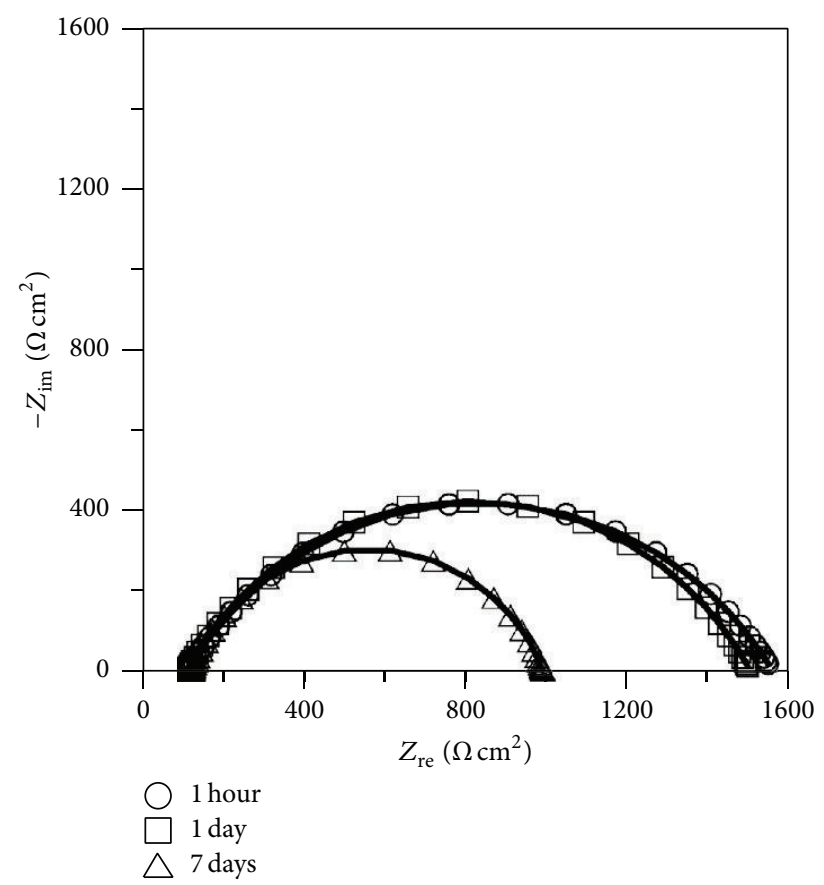

(a)

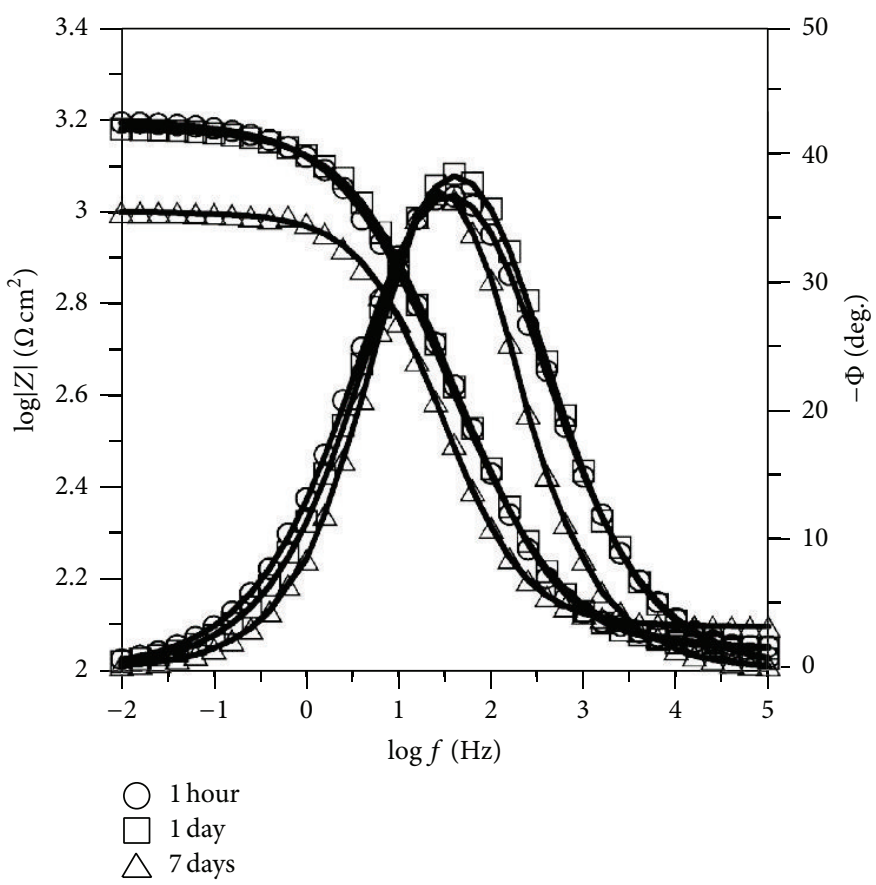

(b)

FIGURE 5: Nyquist plot (a) and Bode plot (b) recorded for uncoated FeMnSi alloy after different immersion times in $\mathrm{HBSS}^{\circ}$ at $37^{\circ} \mathrm{C}$, measured at open circuit potential.

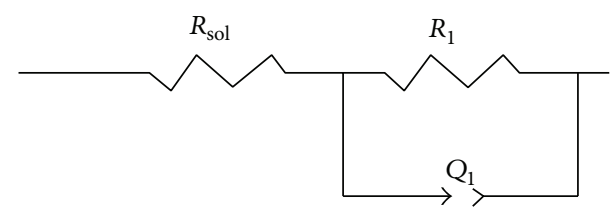

(a)

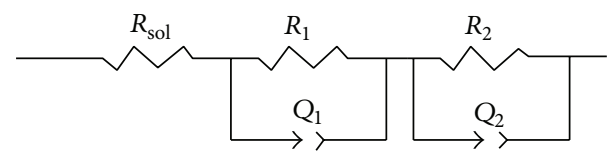

(b)

Figure 6: Equivalent circuits (ECs) used to fit the impedance data.

Figure 8 displays the experimental linear potentiodynamic polarization curves, after 7 days of immersion time in HBSS at $37^{\circ} \mathrm{C}$, for the uncoated and $\mathrm{HA}-\mathrm{ZrO}_{2}$-coated FeMnSi samples.

The zero current potential (ZCP) and corrosion current density $\left(j_{\text {corr }}\right)$ values were determined by Tafel analysis for a range of $\pm 100 \mathrm{mV}$ around of ZCP. The average values of zero current potential (ZCP) and corrosion current density $\left(j_{\text {corr }}\right)$ determined from the polarization curves are presented in Table 4 . The polarization curves showed a clear difference between the uncoated and $\mathrm{HA}-\mathrm{ZrO}_{2}$-coated $\mathrm{FeMnSi}$ alloys.

The $\mathrm{ZCP}$ of the $\mathrm{HA}+\mathrm{ZrO}_{2}$-coated FeMnSi alloy was shifted towards a more negative potential, indicating a porous film formed on the surface [34]. The corrosion current density $\left(j_{\text {corr }}\right)$ is representative of the degradation degree of the alloy. It is evident from Figure 5 that there is a decrease of the corrosion current density of the $\mathrm{HA}-\mathrm{ZrO}_{2}$-coated sample with respect to the uncoated sample. The corrosion current density for uncoated $\mathrm{FeMnSi}$ alloy is approximately three times bigger than in the case of $\mathrm{HA}-\mathrm{ZrO}_{2}$-coated FeMnSi alloy, when they were obtained in the same conditions. In the case of both $\mathrm{HA}-\mathrm{ZrO}_{2}$-coated and uncoated samples, the anodic current shows a monotonically increase as the polarization is made positive from the ZCP, related the dissolution process. The observations confirm the trends presented above from EIS experiments.

A generalized corrosion of the uncoated FeMnSi surface alloy was confirmed by SEM examination of the retrieved sample after completing the polarization tests (Figure 9(a)). Figure 9(b) presents the SEM of $\mathrm{HA}-\mathrm{ZrO}_{2}$-coated FeMnSi alloy after LPP in $\mathrm{HBSS}$ at $37^{\circ} \mathrm{C}$. After polarization at $+1 \mathrm{~V}$ in HBSS the thin HA film is cracked and exfoliated in different locations by corrosion process. The uncoated FeMnSi alloy presents a preferential corrosion, based on the orientation of the equiaxial grains. Those with perpendicular fibers, indicated by arrows in Figure 9(a), present a higher corrosion compared to those with longitudinal fibers.

In the coated sample case (Figure 9(b)), the LPP test determined corrosion compounds formation (on the top of surface) and exfoliations in some parts of the material. However, silicon and zirconium present a good stability and 
TABLE 3: Electrochemical parameters obtained from EIS spectra using the selected EC for the $\left(\mathrm{HA}-\mathrm{ZrO}_{2}\right)$ coated FeMnSi alloy after different immersion time in HBSS, at $37^{\circ} \mathrm{C}$.

\begin{tabular}{lcccccc}
\hline Time & $Q_{1}\left(\mu \mathrm{S} \mathrm{cm}^{-2} \mathrm{~s}^{n}\right)$ & $n_{1}$ & $R_{1}\left(\mathrm{k} \Omega \mathrm{cm}^{2}\right)$ & $Q_{2}\left(\mu \mathrm{Scm}^{-2} \mathrm{~s}^{n}\right)$ & $n_{2}$ & $R_{2}\left(\mathrm{k} \Omega \mathrm{cm}^{2}\right)$ \\
\hline 1 hour & 330 & 0.80 & 0.5 & 39 & 44 & 0.81 \\
1 day & 370 & 0.80 & 0.4 & 51 & 0.81 & 3.8 \\
7 days & 430 & 0.79 & 0.2 & 0.80 & 2.5 \\
\hline
\end{tabular}

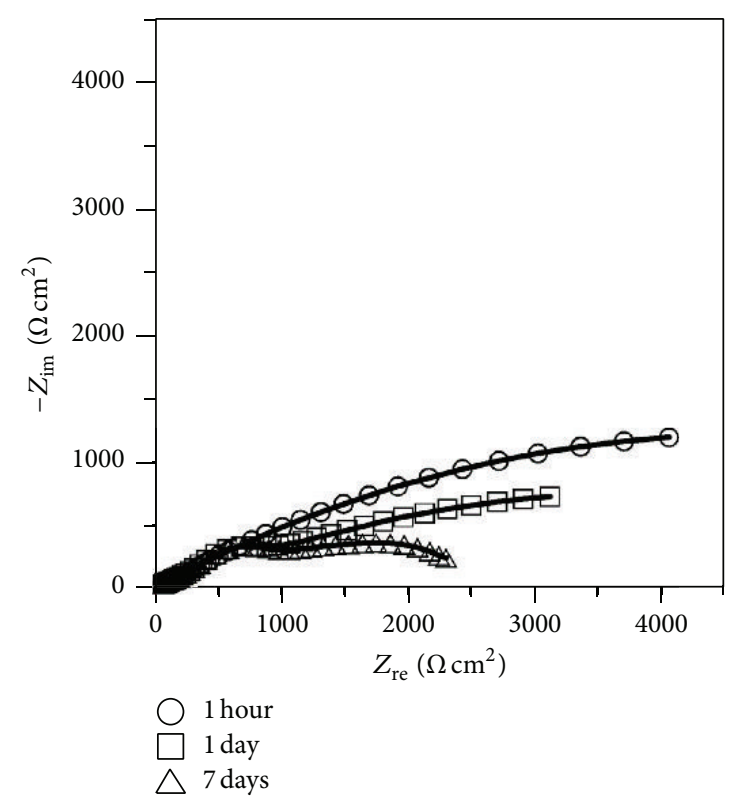

(a)

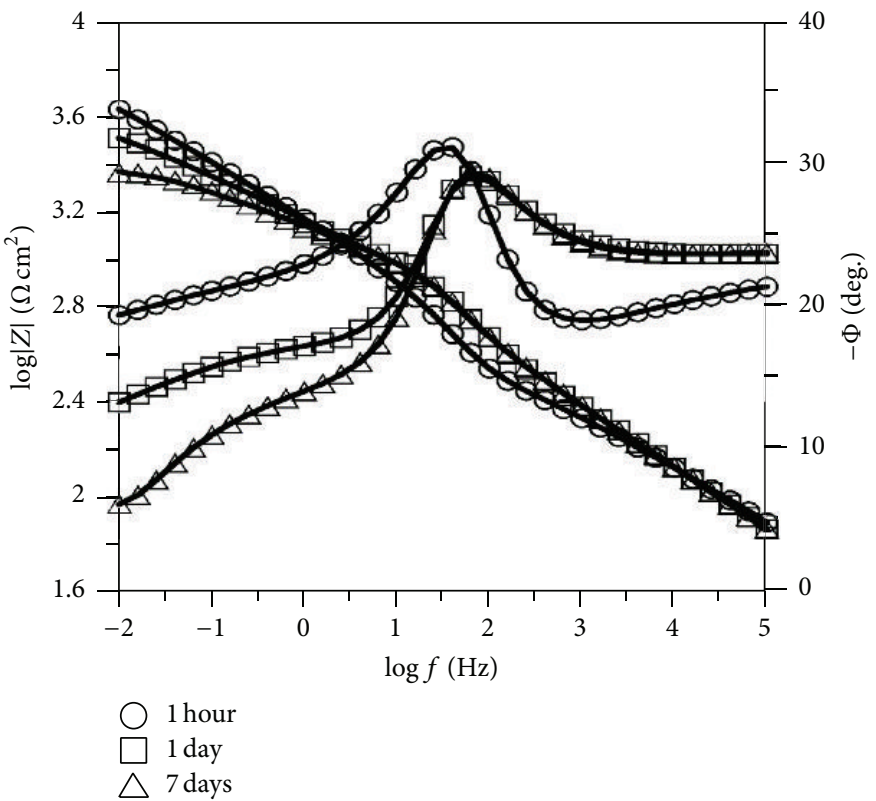

(b)

Figure 7: Nyquist plot (a) and Bode plot (b) recorded for $\mathrm{HA}-\mathrm{ZrO}_{2}$-coated $\mathrm{FeMnSi}$ alloy after different immersion times in $\mathrm{HBSS}$ at $37^{\circ} \mathrm{C}$, measured at open circuit potential.

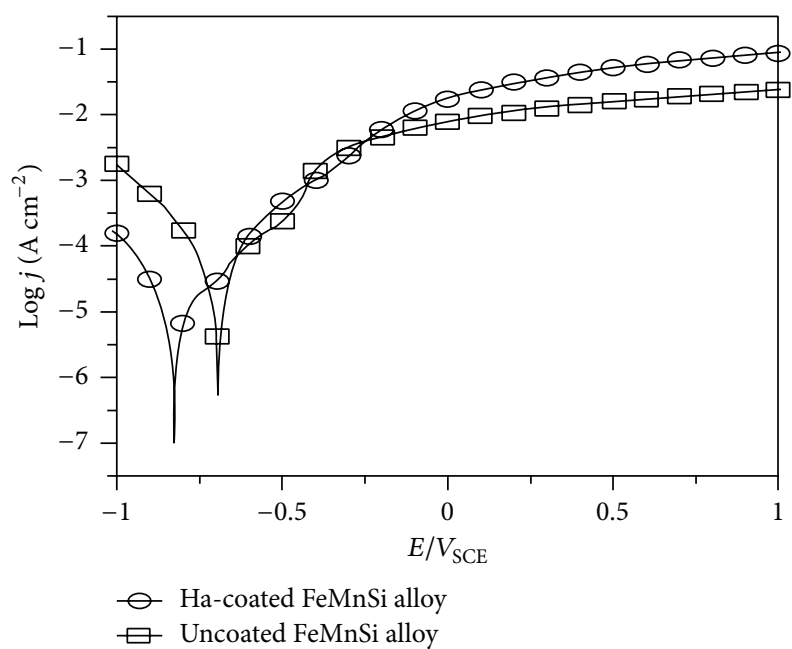

FIGURE 8: Linear potentiodynamic polarization curves for both $\mathrm{HA}-\mathrm{ZrO}_{2}$-coated and uncoated FeMnSi alloys in HBSS. Scan rate: $0.5 \mathrm{mV} \mathrm{s}^{-1}$.

$\mathrm{Na}, \mathrm{Mg}$, and $\mathrm{Cl}$ form new compounds on the surface together with the oxides which are predominant [25].
TABLE 4: Electrochemical parameters (average (standard deviation)) determined from linear potentiodynamic polarization curves measured for both $\left(\mathrm{HA}-\mathrm{ZrO}_{2}\right)$ coated and uncoated FeMnSi alloys in HBSS, at $37^{\circ} \mathrm{C}$.

\begin{tabular}{lcc}
\hline FeMnSi alloy & $\mathrm{ZCP}(\mathrm{mV}$ versus SCE $)$ & $j_{\text {corr }}\left(\mu \mathrm{A} \mathrm{cm}^{-2}\right)$ \\
\hline${\left.\mathrm{HA}-\mathrm{ZrO}_{2}\right) \text { coated }}_{\text {Uncoated }}$ & $-825(13)$ & $18(0.4)$ \\
\hline
\end{tabular}

\section{Conclusions}

A new biodegradable FeMnSi alloy was developed. The electrochemical behavior of uncoated and PLD hydroxyapatite coatings on FeMnSi alloys was evaluated by electrochemical impedance spectroscopy (EIS) and linear potentiodynamic polarization (LPP) in HBSS, at $37^{\circ} \mathrm{C}$. EIS measurements showed that corrosion process for both $\mathrm{HA}-\mathrm{ZrO}_{2}$-coated and uncoated FeSiMn were under charge transfer control. The EIS results exhibited small resistance values (order $10^{2} \Omega \mathrm{cm}^{2}$ ) obtained from medium to low frequency which is indicative of the dissolution process of the corrosion products formed on uncoated FeMnSi alloy. The coating increases the charge transfer resistance for FeMnSi substrate in HBSS. The corrosion current density for uncoated FeMnSi alloy is 


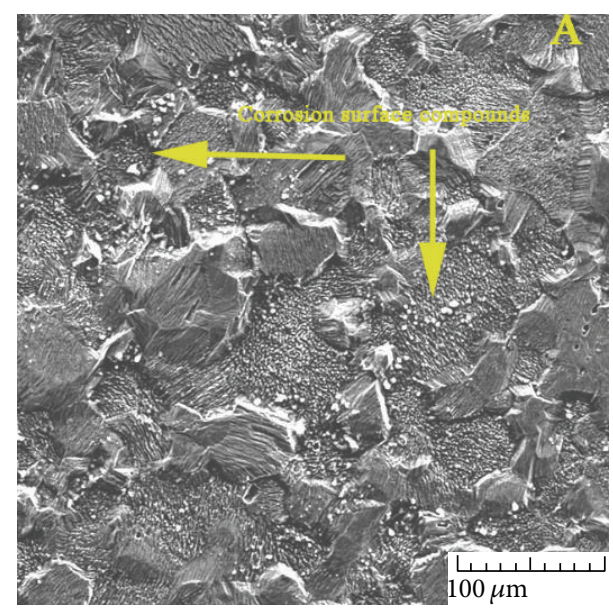

(a)

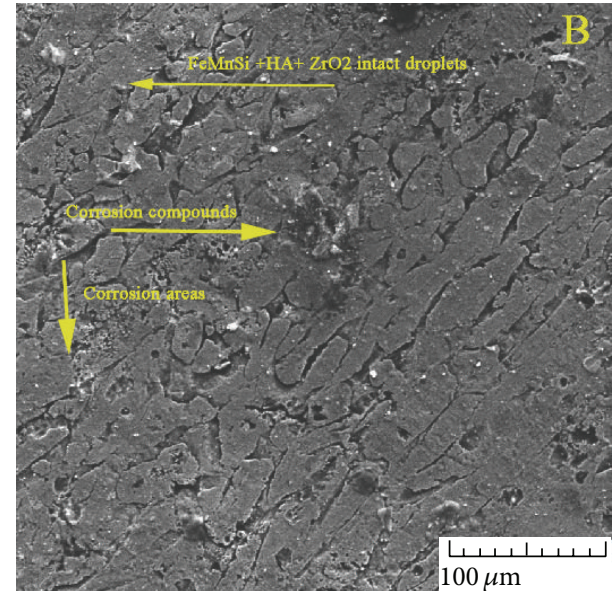

(b)

FIGURE 9: SEM micrographs of FeMnSi surface: (a) heat treated sample uncoated and (b) coated, after linear potentiodynamic polarization at $1 \mathrm{~V}$ in $\mathrm{HBSS}$, at $37^{\circ} \mathrm{C}$.

approximately three times bigger than in the case of the HA$\mathrm{ZrO}_{2}$-coated FeMnSi alloy. Using SEM, both uncoated and $\mathrm{HA}-\mathrm{ZrO}_{2}$-coated FeMnSi alloy showed degradation during the polarization test. These in vitro results will assure the background for carrying out in vivo biological tests. Satisfactory results from this complementary analysis must also be obtained before using the $\mathrm{HA}-\mathrm{ZrO}_{2}$-coated FeMnSi alloy for biomedical applications.

\section{Conflict of Interests}

The authors declare that there is no conflict of interests regarding the publication of this paper.

\section{References}

[1] M. Niinomi, T. Hattori, K. Morikawa et al., "Development of low rigidity $\beta$-type titanium alloy for biomedical applications," Materials Transactions, vol. 43, no. 12, pp. 2970-2977, 2002.

[2] J. Nagels, M. Stokdijk, and P. M. Rozing, "Stress shielding and bone resorption in shoulder arthroplasty," Journal of Shoulder and Elbow Surgery, vol. 12, no. 1, pp. 35-39, 2003.

[3] D. Tie, F. Feyerabend, N. Hort et al., "In vitro mechanical and corrosion properties of biodegradable Mg-Ag alloys," Materials and Corrosion, vol. 65, no. 6, pp. 569-576, 2014.

[4] R. Zeng, W. Dietzel, F. Witte, N. Hort, and C. Blawert, "Progress and challenge for magnesium alloys as biomaterials," Advanced Engineering Materials, vol. 10, no. 8, pp. B3-B14, 2008.

[5] D. Xue, Y. Yun, M. J. Schulz, and V. Shanov, "Corrosion protection of biodegradable magnesium implants using anodization," Materials Science and Engineering C, vol. 31, no. 2, pp. 215-223, 2011.

[6] P. Rosemann, J. Schmidt, and A. Heyn, "Short and long term degradation behaviour of $\mathrm{Mg}-1 \mathrm{Ca}$ magnesium alloys and protective coatings based on plasma-chemical oxidation and biodegradable polymer coating in synthetic body fluid," Materials and Corrosion, vol. 64, no. 8, pp. 714-722, 2013.
[7] M. Niinomi, "Mechanical biocompatibilities of titanium alloys for biomedical applications," Journal of the Mechanical Behavior of Biomedical Materials, vol. 1, no. 1, pp. 30-42, 2008.

[8] Z. Li, X. Gu, S. Lou, and Y. Zheng, "The development of binary $\mathrm{Mg}$-Ca alloys for use as biodegradable materials within bone," Biomaterials, vol. 29, no. 10, pp. 1329-1344, 2008.

[9] L. Reclaru, R. Ziegenhagen, P.-Y. Eschler, A. Blatter, and J. Lemaître, "Comparative corrosion study of 'Ni-free' austenitic stainless steels in view of medical applications," Acta Biomaterialia, vol. 2, no. 4, pp. 433-444, 2006.

[10] S. B. Goldhaber, "Trace element risk assessment: essentiality vs. toxicity," Regulatory Toxicology and Pharmacology, vol. 38, no. 2, pp. 232-242, 2003.

[11] Q. Chen and G. A. Thouas, "Metallic implant biomaterials," Materials Science and Engineering R: Reports, vol. 87, pp. 1-57, 2014.

[12] A. Subic, M. A. Gibson, J. Mohd Jani, and M. Leary, "A review of shape memory alloy research, applications and opportunities," Materials and Design, vol. 56, pp. 1078-1113, 2014.

[13] B. Wegener, B. Sievers, S. Utzschneider et al., "Microstructure, cytotoxicity and corrosion of powder-metallurgical iron alloys for biodegradable bone replacement materials," Materials Science and Engineering B, vol. 176, no. 20, pp. 1789-1796, 2011.

[14] M. Schinhammer, A. C. Hänzi, J. F. Löffler, and P. J. Uggowitzer, "Design strategy for biodegradable Fe-based alloys for medical applications," Acta Biomaterialia, vol. 6, no. 5, pp. 1705-1713, 2010.

[15] M. Fantanariu, L. C. Trinca, C. Solcan et al., "A new Fe-Mn-Si alloplastic biomaterial as bone grafting material: in vivo study," Applied Surface Science, vol. 352, pp. 129-139, 2015.

[16] L. C. Trincă, M. Fântânariu, C. Solcan et al., "In vivo degradation behavior and biological activity of some new $\mathrm{Mg}$-Ca alloys with concentration's gradient of Si for bone grafts," Applied Surface Science, vol. 352, pp. 140-150, 2015.

[17] W. Zhang, M. Li, Q. Chen, W. Hu, W. Zhang, and W. Xin, "Effects of Sr and Sn on microstructure and corrosion resistance of $\mathrm{Mg}-\mathrm{Zr}-\mathrm{Ca}$ magnesium alloy for biomedical applications," Materials \& Design, vol. 39, pp. 379-383, 2012. 
[18] Y.-H. Kim, J.-S. Kim, W. Huh, and K.-H. Lee, "Weight of polyethylene wear particles is similar in TKAs with oxidized zirconium and cobalt-chrome prostheses," Clinical Orthopaedics and Related Research, vol. 468, no. 5, pp. 1296-1304, 2010.

[19] S. Yugeswaran, C. P. Yoganand, A. Kobayashi, K. M. Paraskevopoulos, and B. Subramanian, "Mechanical properties, electrochemical corrosion and in-vitro bioactivity of yttria stabilized zirconia reinforced hydroxyapatite coatings prepared by gas tunnel type plasma spraying," Journal of the Mechanical Behavior of Biomedical Materials, vol. 9, pp. 22-33, 2012.

[20] A. Arifin, A. B. Sulong, N. Muhamad, J. Syarif, and M. I. Ramli, "Material processing of hydroxyapatite and titanium alloy (HA/Ti) composite as implant materials using powder metallurgy: a review," Materials \& Design, vol. 55, pp. 165-175, 2014.

[21] S. G. Hansen and T. E. Robitaille, "Formation of polymer films by pulsed laser evaporation," Applied Physics Letters, vol. 52, no. 1, pp. 81-83, 1988.

[22] S. G. Hansen, "Velocity profiles of species ejected in ultraviolet laser ablation of several polymers examined by time-of-flight mass spectroscopy," Journal of Applied Physics, vol. 66, no. 7, pp. 3329-3336, 1989.

[23] H. Hermawan, H. Alamdari, D. Mantovani, and D. Dubé, "Iron-manganese: new class of metallic degradable biomaterials prepared by powder metallurgy," Powder Metallurgy, vol. 51, no. 1, pp. 38-45, 2008.

[24] A. K. Sinha, Ferrous Physical Metallurgy, Butterworths, London, UK, 1989.

[25] M. Rațoi, G. Dascălu, T. Stanciu et al., "Preliminary results of $\mathrm{FeMnSi+Si(PLD)} \mathrm{alloy} \mathrm{degradation,"} \mathrm{Key} \mathrm{Engineering} \mathrm{Materials,}$ vol. 638, pp. 117-122, 2015.

[26] D. Mareci, R. Chelariu, G. Ciurescu, D. Sutiman, and T. Gloriant, "Electrochemical aspects of Ti-Ta alloys in HBSS," Materials and Corrosion, vol. 61, no. 9, pp. 768-774, 2010.

[27] N. Cimpoeşu, S. Stanciu, P. Vizureanu, R. Cimpoeşu, D. Cristian Achiţei, and I. Ioniţă, "Obtaining shape memory alloy thin layer using PLD technique," Journal of Mining and Metallurgy, Section B: Metallurgy, vol. 50, no. 1, pp. 69-76, 2014.

[28] O. G. Pompilian, G. Dascalu, I. Mihaila et al., "Pulsed laser deposition of rare-earth-doped gallium lanthanum sulphide chalcogenide glass thin films," Applied Physics A, vol. 117, no. 1, pp. 197-205, 2014.

[29] J. R. Macdonald, "Impedance spectroscopy," in Emphasizing Solid Materials and Systems, vol. 39, John Wiley \& Sons, New York, NY, USA, 1979.

[30] I. Thompson and D. Campbell, "Interpreting Nyquist responses from defective coatings on steel substrates," Corrosion Science, vol. 36, no. 1, pp. 187-198, 1994.

[31] C. Liu, Q. Bi, and A. Matthews, "EIS comparison on corrosion performance of PVD TiN and CrN coated mild steel in $0.5 \mathrm{~N}$ $\mathrm{NaCl}$ aqueous solution," Corrosion Science, vol. 43, no. 10, pp. 1953-1961, 2001.

[32] R. M. Souto, M. M. Laz, and R. L. Reis, "Degradation characteristics of hydroxyapatite coatings on orthopaedic TiAlV in simulated physiological media investigated by electrochemical impedance spectroscopy," Biomaterials, vol. 24, no. 23, pp. 42134221, 2003.

[33] D. H. Yang, C. L. Liu, X. P. Liu, M. Qi, and G. Q. Lin, "EIS diagnosis on the corrosion behavior of TiN coated NiTi surgical alloy," Current Applied Physics, vol. 5, no. 5, pp. 417-421, 2005.
[34] B. M. Fernández-Pérez, J. A. González-Guzmán, S. González, and R. M. Souto, "Electrochemical impedance spectroscopy investigation of the corrosion resistance of a waterborne acrylic coating containing active electrochemical pigments for the protection of carbon steel," International Journal of Electrochemical Science, vol. 9, no. 4, pp. 2067-2069, 2014.

[35] I. C. Lavos-Valereto, I. Costa, and S. Wolynec, "The electrochemical behavior of Ti-6Al-7Nb alloy with and without plasma-sprayed hydroxyapatite coating in Hank's solution," Journal of Biomedical Materials Research, vol. 63, no. 5, pp. 664$670,2002$. 

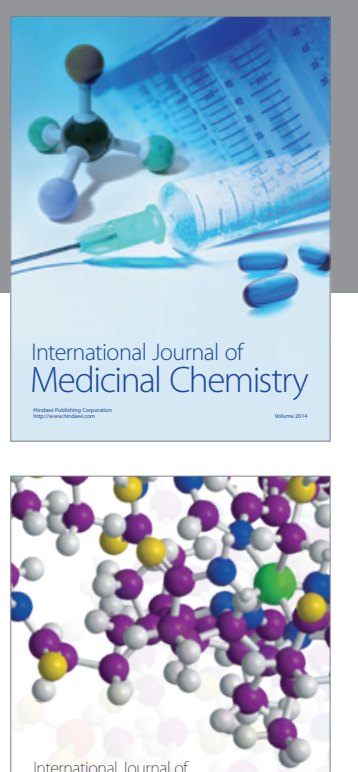

Carbohydrate Chemistry

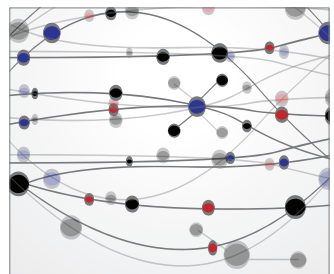

The Scientific World Journal
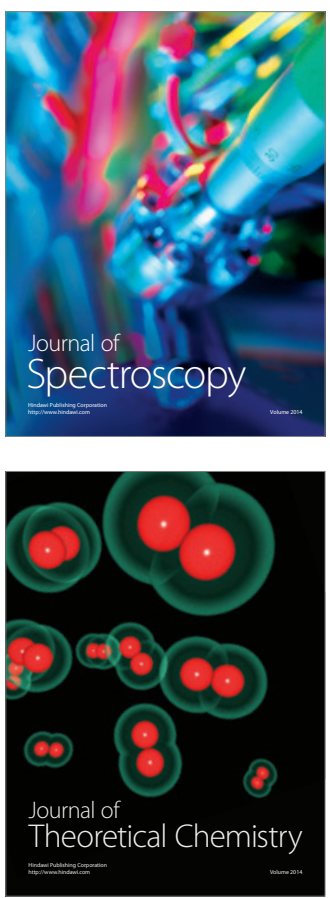
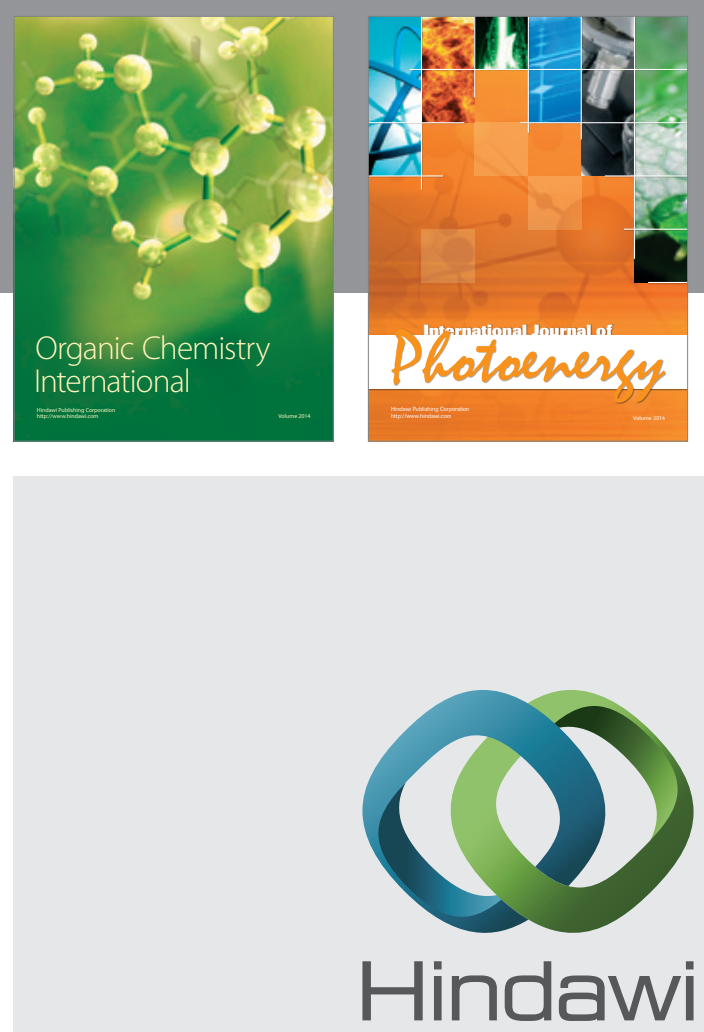

Submit your manuscripts at

http://www.hindawi.com

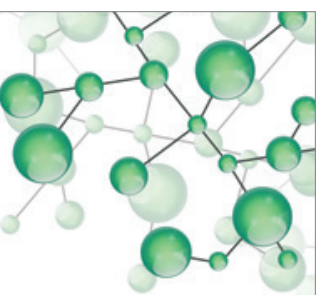

International Journal of

Inorganic Chemistry

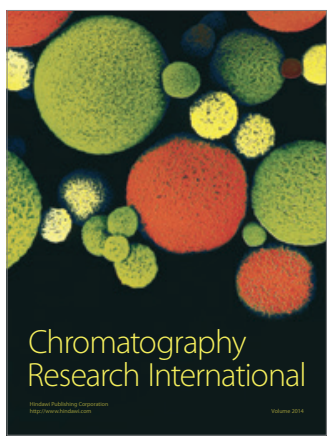

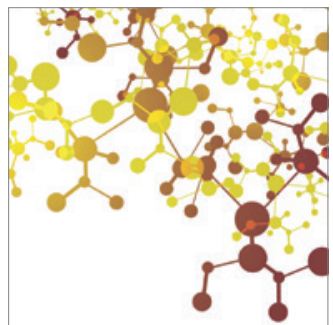

Applied Chemistry
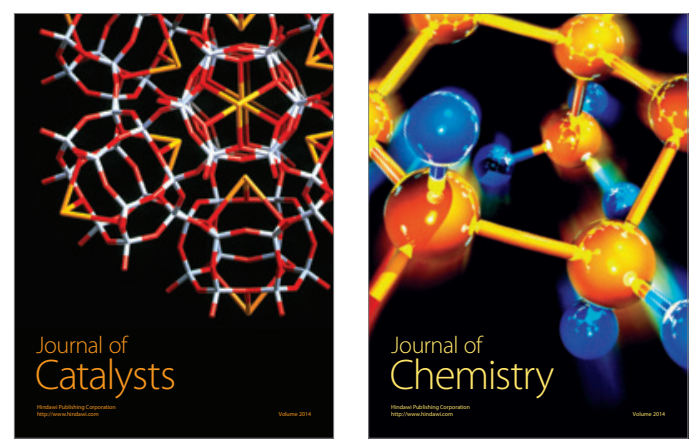
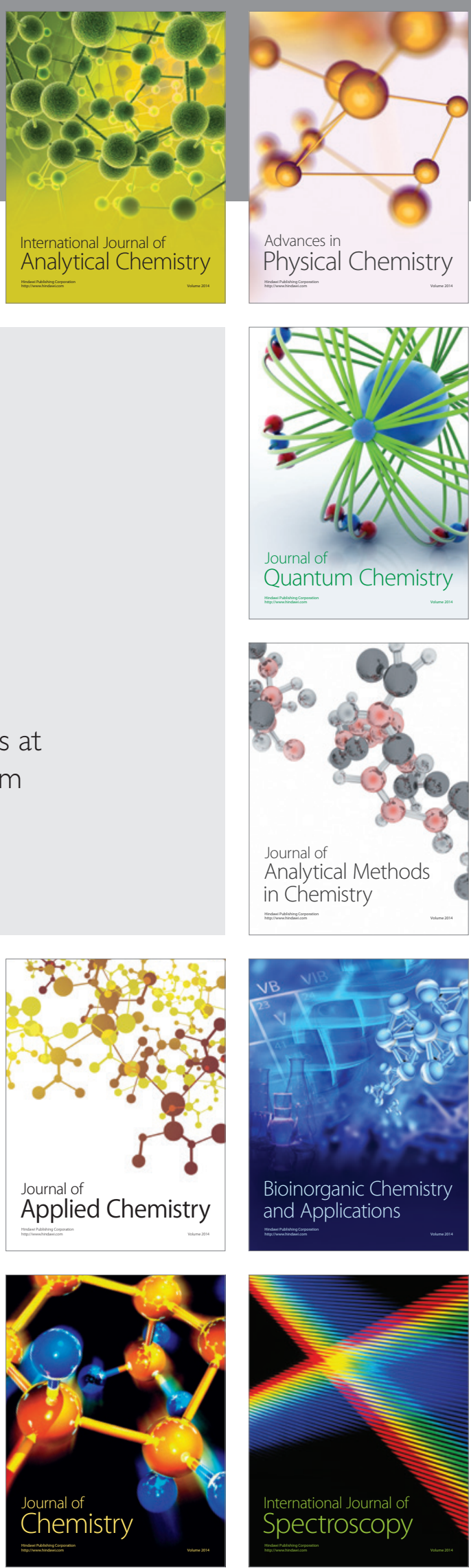